\title{
A STOCHASTIC FUZZY CONTROLLED RESONANT CONVERTER FOR DISCHARGE LAMPS WITH PFC
}

\author{
M. VIJAYASANTHI ${ }^{1} \&$ M. SUSHAMA ${ }^{2}$ \\ ${ }^{l}$ EEE, CMR College of Engineering \& Technology, Secunderabad, Telangana, India \\ ${ }^{2}$ EEE, JNTUH, Hyderabad, Telangana, India
}

\begin{abstract}
The brightness of discharge lamps is controlled by varying the frequency of the resonant converter for high efficiency operation. In this paper we introduce a resonant converter with a magnetic energy recovery switch along with power factor correction. The PFC converter generates DC voltage controlled by fuzzy controller as a feedback system connected to discharge lamp through high frequency resonant converter. The complete analysis with different frequencies and graphical representations of output voltage and current of the lamp are presented using MATLAB software with dynamic operating states.
\end{abstract}

KEYWORDS: Resonant Converter, Fuzzy Logic, PFC, Discharge Lamp \& Ballistic Inductance

Received: Jan 28, 2017; Accepted: Mar 12, 2017; Published: Mar 16, 2017; Paper Id.: IJEEERAPR20177

\section{INTRODUCTION}

Most of the lamp applications in commercial or industrial usage need brightness control with respect to the demand by the user. In conventional controller a resistive type control is adopted for the brightness control which has high conduction loses. With high power consumption of the lamp the power loss during the control of brightness is also high. It is very vital to save the energy consumed by the lamp and increase the efficiency. Due to the plasma characteristics of the discharge lamps it is very difficult to control the brightness. By controlling the voltage amplitude using variable resistor in series works for filament lamps but the same may not be suitable for discharge lamps [1]. Several research papers are released with emphasis on brightness control of discharge lamps and efficiency with drawbacks of complicated designs and uneconomical costs of the circuit topologies. The high frequency operation of the converter leads to acoustic resonance problems reducing the reliability of the converter and also the lamp. To avoid this issue of acoustic resonance magnetic ballast has to be introduced in place of electronic ballast [1].

The replacement of electronic ballast with magnetic ballast may increase complications during the construction of the circuit topology. There are many traditional methods for ballast applications [2] in which the most common method [2] is changeable ballast inductance method with different possible ballasts on the lamp. The ballast control can only be done by step process as the resolution of inductance values may not be high. The brightness of the lamp cannot be adjusted precisely to a specific value, to overcome this issue larger values of inductances need to be taken which increases the size, weight and cost of the ballast circuit topology [2]. Discharge lamps are categorized into High Intensity discharge lamps and fluorescent lamps. High intensity discharge lamps include metal halide lamps, mercury lamps and high pressure sodium lamps. As compared to fluorescent lamps, HID lamp brightness is more difficult to control but the brightness levels and efficiency are far 
better than the fluorescent lamps. With the high brightness capability the HID lamps are used for outdoor purpose, which may be street lighting flood lights etc., These HID lamps can only operate either with $100 \%$ ON or completely OFF and a major disadvantage is we cannot turn ON the lamp immediately when it is switched OFF and can be only turned ON when the lamp temperature goes low. This state of operation of the lamp indicates that frequent switching [4] of the lamp is not possible and with high stating current the life of the lamp is also reduced.

To overcome this problem we introduce a new brightness control ballast circuit topology in this paper for both High intensity discharge lamps and also fluorescent lamps. The circuit diagram of high frequency PFC with feedback control loop can be seen below in figure 1

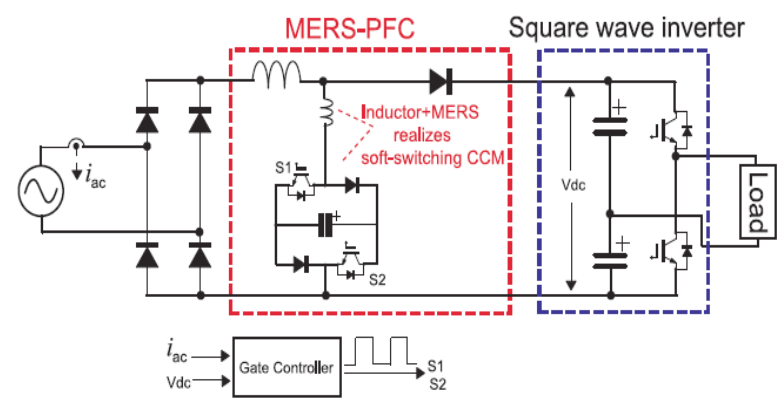

Figure 1: Magnetic Ballast PFC Circuit Topology

The input of the converter is a single phase AC input with voltage $230 \mathrm{Vrms}$ and frequency $50 \mathrm{~Hz}$ fed to a full bridge diode rectifier converting AC to variable DC. The variable DC output of the rectifier is fed to MERS (Magnetic Energy Recovery Switch) PFC (Power Factor Corrector) circuit. The output of the converter is further connected to a high frequency square wave resonant [3] converter which powers the HID lamp (load). The MERS includes a smoothing input inductor with soft switching inductor with two controlled forced commutation power electronic switches and four uncontrolled diodes with a capacitor in the DC side of the MERS converter. Both the power electronic switches operate simultaneously to which same gate signal is given.

\section{MODES of OPERATION}

The MERS [7] circuit operates in four modes with change in the switching states of the power electronic switches.

Mode 1: In this mode assuming the capacitor is initially in charged state, which discharges when both the IGBTs are turned ON through the power supply. To maintain zero current switching of the converter, input inductor Ls resists the current flowing from the input source to increase from zero achieving zero current switching operation.

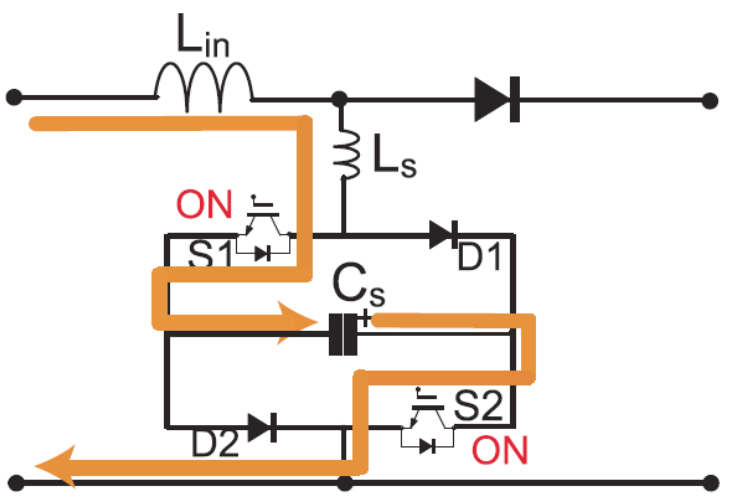


Figure 2: Mode 1 Operation of MERS

Mode 2: In this mode of operation when the capacitor completely discharges the circuit jumps into parallel conduction mode where both IGBTs and both diagonal diodes are in conduction mode until both IGBTs are turned OFF.

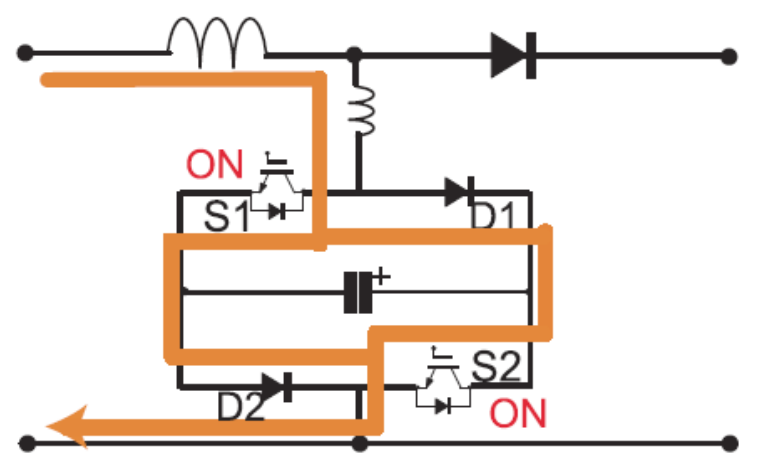

Figure 3: Mode 2 Operation of MERS

Mode 3: This mode of operation starts when both IGBTs are turned OFF, with conduction of current through only diagonal diodes with charging the capacitor. As the capacitor is completely discharged in mode 1 the capacitor voltage charging starts from zero, which may be considered as zero voltage switching of the IGBTs. When the capacitor charges to the amplitude slightly higher than the input rectifier voltage the outer diode starts conducting and current in the MERS circuit is diverted to square wave inverter.

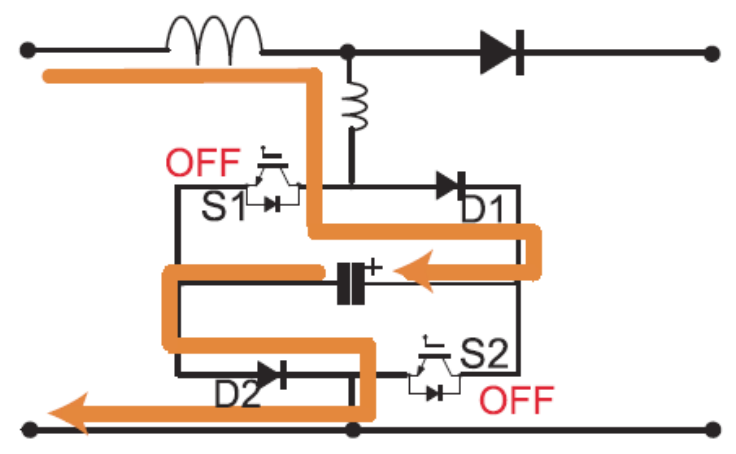

Figure 4: Mode 3 Operation of MERS

Mode 4: When the current through the MERS circuit is completely decreased to zero, the outer diode conducts until the IGBTs are turned ON again with mode 1 switching operation.

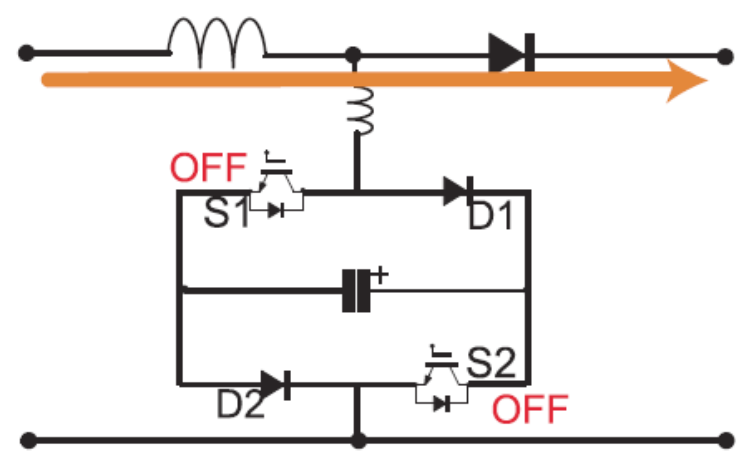

Figure 4: Mode 4 Operation of MERS 


\section{DESCRIPTION OF CONTROL STRUCTURE}

The controller of the MERS circuit topology controls the duty ratio of the IGBTs switching states. The duty ratio of the controller is dynamically controlled by PI controller with an error input achieved by comparison of 'iac' (Input current RMS value) with MERS output DC voltage amplitude. The control structure block diagram is given below.

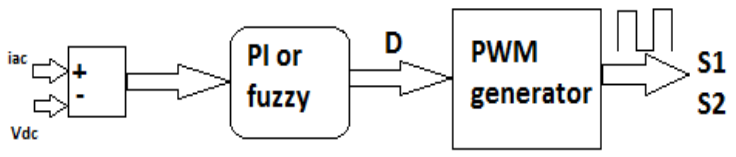

Figure 5: Control Block Diagram of MERS

In the control structure it can be clearly observed that the PI or Fuzzy controllers [6] generate Duty ratio which is compared to a triangular wave with a specific frequency (very much higher than the input frequency) generating a pulse given to both the IGBTs simultaneously. The proportional and integral gain values are taken as $\mathrm{Kp}=0.012, \mathrm{Ki}=10^{-5}$ respectively. The fuzzy structure is designed with seven input and seven output membership functions with a total of 49 rules according to the rule base shown below.

\begin{tabular}{|c|c|c|c|c|c|c|c|c|}
\hline & & & & & e & $\rightarrow$ & & \\
\hline & & NB & NM & NS & EZ & PS & PM & PB \\
\hline & PB & $\mathbf{Z}$ & PS & PM & PB & PB & PB & PB \\
\hline & PM & NS & $\mathbf{Z}$ & PS & PM & PB & PB & PB \\
\hline & PS & NM & NS & $Z$ & PS & PM & $\mathrm{PB}$ & $\mathrm{PB}$ \\
\hline & EZ & NB & NM & NS & 7 & PS & PM & PB \\
\hline & NS & NB & NB & $\mathrm{NM}$ & NS & $\mathbf{Z}$ & PS & PM \\
\hline & NM & NB & $\mathrm{NB}$ & NB & $\mathrm{NM}$ & NS & $\mathbf{Z}$ & PS \\
\hline & NB & NB & NB & NB & NB & NM & NS & $\mathbf{Z}$ \\
\hline
\end{tabular}

Figure 6: 49 Rule Table for Fuzzy Structure

The duty ratio output generation with control of output voltage amplitude of the lamp will be discussed in next section.

\section{SIMULATION RESULTS AND DISCUSSIONS}

As per the given figure 1 the model is designed in MATLAB Simulink software with complete graphical representations with operation descriptions. The below figure is the Simulink modeling of the given circuit topology.

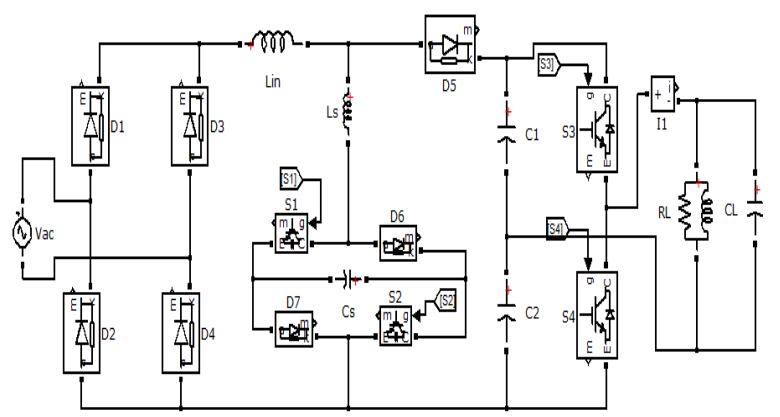

Figure 7: Simulink Model of Mers Pfc Circuit with Hid Lamp

The IGBT switches are controlled with the closed loop control as per the section III. The Simulink model of the 
control structure can be seen below in figure 8. The other two IGBTs of the high frequency inverter [5] are controlled by a pulse generator with high switching frequency of $250 \mathrm{kHz}$.

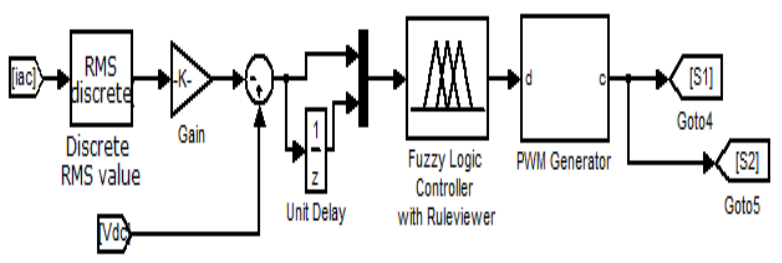

Figure 8: The PI Controlled is Replaced with Fuzzy

The fuzzy controller has two inputs, in which one is error (e) output of the comparison of 'iac' and 'Vdc' and the other is the change in error (de) with seven membership functions for each input. The output value generation with specific ' $\mathrm{e}$ ' and 'de' input with reference to the rule base can be seen below in figure 9

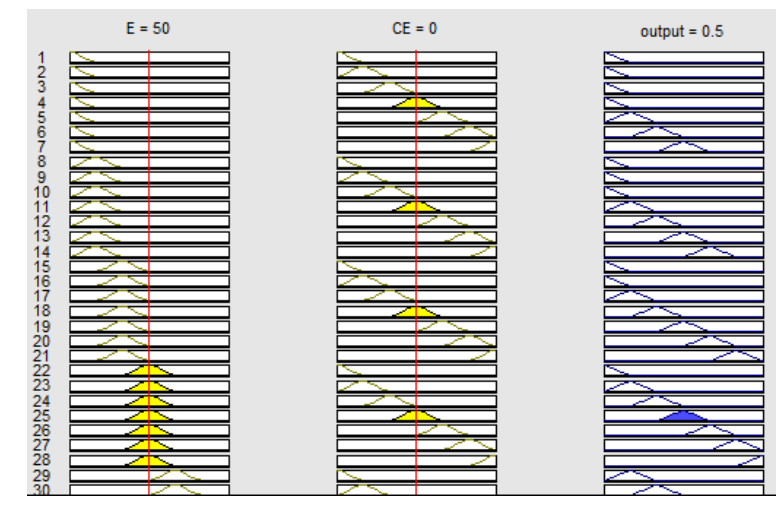

Figure 9: Output Generation for 49 Rule Base

A comparison of DC voltage Vdc for PI and fuzzy are taken with Input voltage, Input current, Lamp voltage and lamp current with also power factor measurement graph.

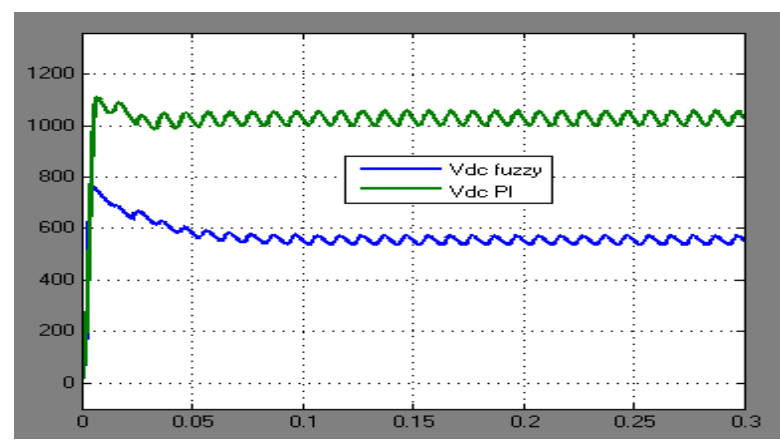

Figure 10: Vdc Comparison of Pi and Fuzzy 


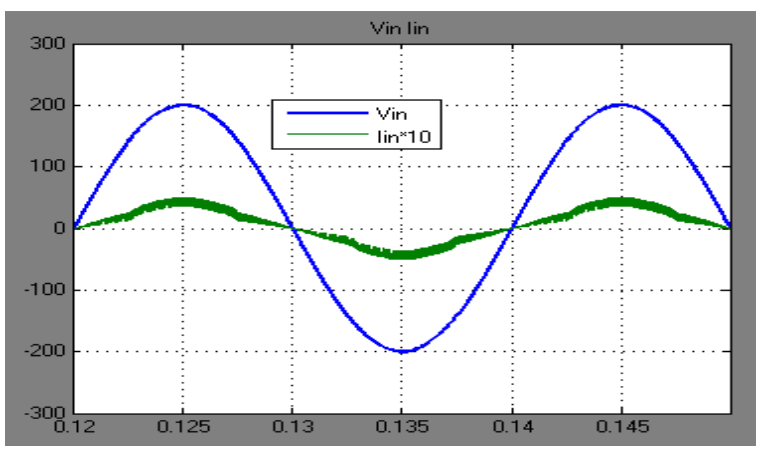

Figure 11: Input Voltage and Input Current

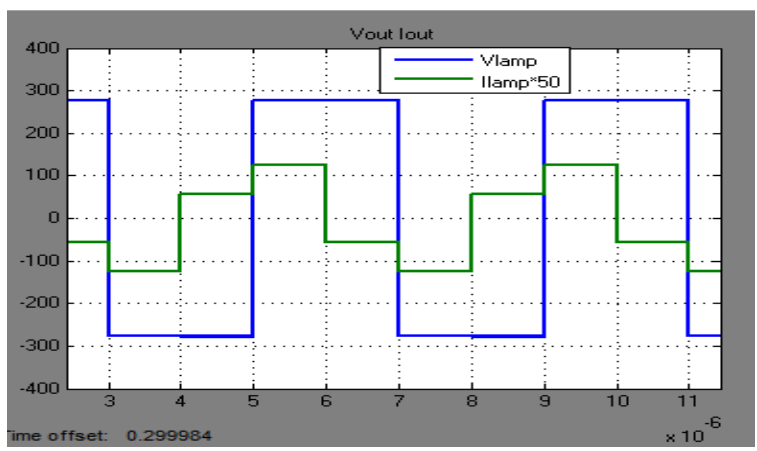

Figure 12: Lamp Voltage and Lamp Current

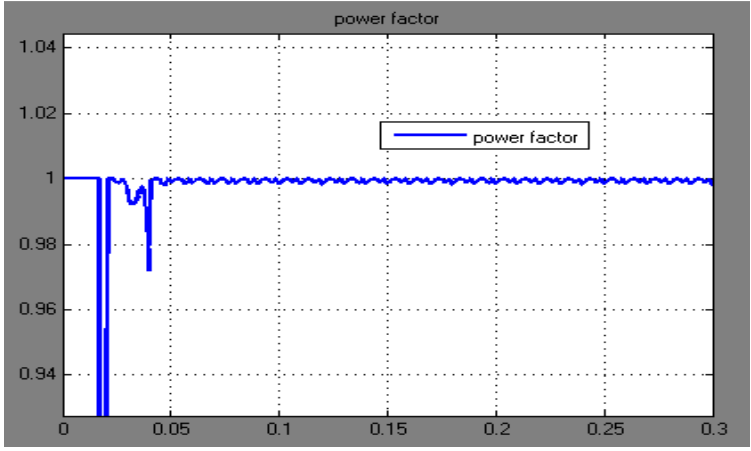

Figure 13: Input Power Factor

\section{CONCLUSIONS}

With the above given results comparison of the converter with fuzzy and PI, it can be observed that the DC voltage of MERS is more stable with less initial peak overshoot and ripple. With the given result the MERS circuit topology is more stable and reliable for fuzzy structure controlled IGBTs. The values for the input sources with MERS and lamp passive element values are given below in TABLE I.

Table 1

\begin{tabular}{|l|c|c|c|}
\hline Vin & $\mathbf{2 0 0 V p , 5 0 H z}$ & $\mathbf{C} \mathbf{1 , C 2}$ & $\mathbf{1 0 0 u F}$ \\
\hline Lin & $2.5 \mathrm{mH}$ & $\mathrm{R}_{\text {LAMP }}$ & 410 \\
\hline Ls & $50 \mathrm{uH}$ & $\mathrm{C}_{\text {LAMP }}$ & $3.6 \mathrm{nF}$ \\
\hline $\mathrm{Cs}$ & $0.03 \mathrm{uF}$ & $\mathrm{L}_{\text {LAMP }}$ & $730 \mathrm{uH}$ \\
\hline
\end{tabular}

\section{REFERENCES}

1. Moo, C.S.; Lin, T.F.; Hsieh, Y.C.; "Single-stage high power factor electronic ballast for fluorescent lamps with constant power 
operation". Electric Power Applications, IEEE Proceedings, Sep. 2001.

2. ANSI C82.11. “American National Standard - For Lamp Ballast - High Frequency Fluorescent Lamp Ballast”. Suplements, 2002.

3. M.C. Cosby and R.M. Nelms, “A resonant inverter for electronic ballast applications," IEEE Transaction on Industrial Electronics, vol. 41, no. 4, pp. 418-425, 2011.

4. J. L. Freitas Vieira, M. A. Co, and L. D. Zorzal, "High power factor electronic ballast based on a single power processing stage," in IEEE PESC'95, 2005, pp. 687-693.

5. de Groot, H., Janssen, E., Pagano, R. and Schetters, K. (2007) Design of a 1-MHz LLC Resonant Converter Based on a DSPDriven SOI Half-Bridge Power MOS Module. IEEE Transactions on Power Electronics, 22, 2307-2320.

6. Madhanakkumar, N., Sivakumaran, T.S., Irusapparajan, G. and Sujitha, D. (2014) Closed Loop Control of LLC Resonant Converter Incorporating ZVS Boost Converter. International Journal of Engineering and Technology,

7. T. Takaku et al., "Power supply for pulsed magnets with magnetic energy recovery current switch," IEEE Transactions on Applied Superconductivity, vol. 14, no. 2, pp. 1794-1797, 2004. 
